\title{
Mechanical Properties and Shear Strength of Sn-3.5Ag-Bi Solder Alloys
}

\author{
Jin-Won Choi *, Ho-Seob Cha* and Tae-Sung Oh \\ Department of Metallurgical Engineering and Materials Science, Hong-Ik University, Seoul 121-791, Korea
}

Mechanical properties and ball shear strength of Sn-3.5Ag-Bi were investigated with Bi addition of 0-9 mass\%. Solder characteristics of $\mathrm{Sn}-3.5 \mathrm{Ag}-\mathrm{Bi}$ were improved with $\mathrm{Bi}$ addition to decrease the melting temperature, to promote wetting to $\mathrm{Cu}$ and $\mathrm{Ni}$ substrates, and to increase the tensile strength and fracture energy. Shear strength of $\mathrm{Sn}-3.5 \mathrm{Ag}-\mathrm{Bi}$ solder bumps increased with Bi addition up to 5 mass $\%$, and was kept almost unchanged with further increase of Bi addition. Shear strength exhibited a parabolic relationship with the tensile fracture energy of the solder alloys.

(Received February 18, 2002; Accepted June 18, 2002)

Keywords: lead-free solder, tin-3.5silver-bismuth, tensile strength, solder bump, shear strength

\section{Introduction}

$\mathrm{Sn}-\mathrm{Pb}$ solders have been predominantly used as an interconnection and joining material in electronic packaging due to low melting temperatures, good mechanical properties, and excellent wettability. However, increased concerns for the environment have demanded the development of lead-free solders. ${ }^{1-4)}$ While investigations on lead-free solders were initiated by the legislative actions to ban $\mathrm{Pb}$ use, the electronic industry confronts lately much strong market pressure for development of lead-free solders from consumers desiring green electronic products. ${ }^{3-5)}$

Among a number of lead-free solders have been developed, ${ }^{1,2)} \mathrm{Sn}-3.5 \mathrm{Ag}$ eutectic solder is one of the attractive candidates to replace eutectic $63 \mathrm{Sn}-37 \mathrm{~Pb}$ in many applications including low-cost electronic products like consumer electronics and computing devices. ${ }^{1-4)}$ Although the melting temperature of $\mathrm{Sn}-3.5 \mathrm{Ag}$ solder is relatively low compared to the melting points of other lead-free solders, it is still considerably higher than $183^{\circ} \mathrm{C}$ of $63 \mathrm{Sn}-37 \mathrm{~Pb}$ eutectic solder. ${ }^{1,2,6)}$ Thus, many works have been conducted to modify the thermal and mechanical characteristics of $\mathrm{Sn}-3.5 \mathrm{Ag}$ solder with addition of $\mathrm{Bi}, \mathrm{Cu}, \mathrm{Sb}$, In, and $\mathrm{Zn}$ as a ternary element. ${ }^{1,3,5-8)}$

In this study, tensile strength and fracture energy of Sn$3.5 \mathrm{Ag}-\mathrm{Bi}$ alloys were characterized with $\mathrm{Bi}$ addition up to 9 mass \%. Sn-3.5Ag-Bi solder bumps were reflowed on BGA (Ball Grid Array) substrates with $\mathrm{Au} / \mathrm{Ni} / \mathrm{Cu} \mathrm{UBM}$ (Under Bump Metallization), and their shear strengths were evaluated with the Bi content.

\section{Experimental Procedure}

$\mathrm{Sn}-3.5 \mathrm{Ag}-\mathrm{Bi}$ alloys were prepared with $\mathrm{Bi}$ addition of 0-9 mass\%. For all samples, the ratio of Ag to Sn was kept the same as the eutectic $\mathrm{Sn}-3.5 \mathrm{Ag}$ composition. Elemental metals were weighed for proper composition, charged in a quartz tube. The quartz tube was sealed under vacuum of $10^{-5} \mathrm{~Pa}$, and the elemental metals were melt and homogeneously mixed at $800^{\circ} \mathrm{C}$ for $3 \mathrm{~h}$ using a rocking furnace. The ingot was remelted at $240^{\circ} \mathrm{C}$ for $30 \mathrm{~min}$ and cooled at the same rate of the reflow profile. The ingot was then ma-

${ }^{*}$ Graduate student, Hong-Ik University. chined to a tensile specimen (Fig. 1) and tensile test was carried out at a strain rate of $3 \times 10^{-4} / \mathrm{s}$. Melting temperatures of $\mathrm{Sn}-3.5 \mathrm{Ag}-\mathrm{Bi}$ solders were measured using DTA (Differential Temperature Analyzer).

To make the solder bumps, Sn-3.5Ag-Bi alloys were rolled to about $30 \mu \mathrm{m}$ thickness and then manually punched out to make discs of $0.8 \mathrm{~mm}$ diameter. $\mathrm{Sn}-3.5 \mathrm{Ag}-\mathrm{Bi}$ solder discs were reflowed at $240^{\circ} \mathrm{C}$ for 30 or $60 \mathrm{sec}$ on $\mathrm{Au}(0.5 \mu \mathrm{m}) / \mathrm{Ni}(5 \mu \mathrm{m}) / \mathrm{Cu}(27 \mu \mathrm{m}) \mathrm{UBM}$ in a RMA flux ambient. Conventional BGA substrate, i.e., photo solder resist (PSR)-defined UBM on bismaleimide triazine (BT)-resin substrate, was used in this study. Figure 2 shows a schematic illustration of a solder bump reflowed on BGA substrate with $\mathrm{Au} / \mathrm{Ni} / \mathrm{Cu} \mathrm{UBM}$.

Ball shear test was conducted using a Dage-2400 shear tester at a constant shear speed of $0.2 \mathrm{~mm} / \mathrm{s}$ with a fixed shear tip height of $0.05 \mathrm{~mm}$ above the solder mask surface. For each experimental condition, more than 30 solder bumps were sheared off in accordance with the JEDEC standard.9) Shear strength was obtained by dividing the shear force with

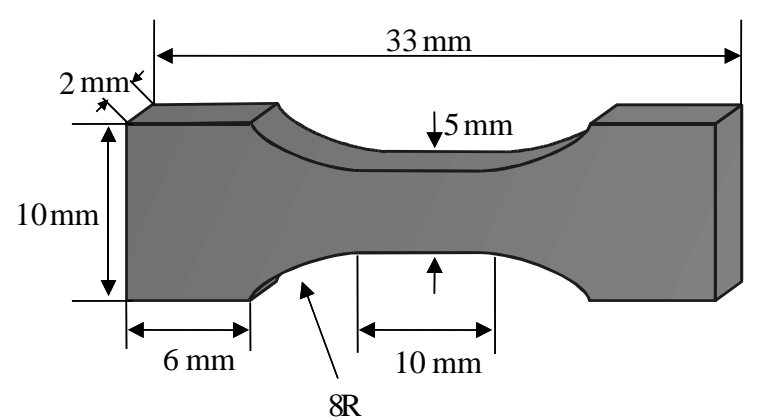

Fig. 1 Schematic illustration of a tensile specimen.

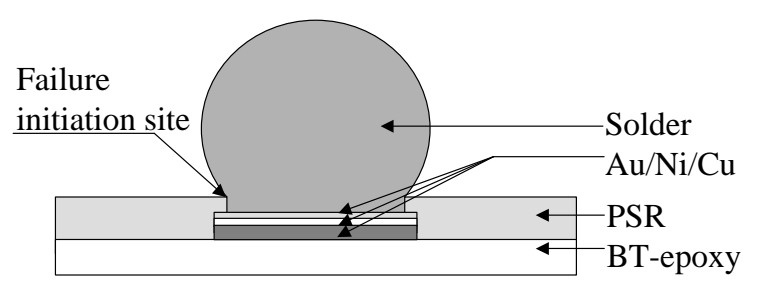

Fig. 2 Schematic illustration of a solder bump reflowed on $\mathrm{Au} / \mathrm{Ni} / \mathrm{Cu}$ UBM. 
the UBM pad area. Microstructure of Sn-3.5Ag-Bi alloys and solder bumps were observed using Scanning electron microscopy (SEM) with Backscattered electron image (BEI).

\section{Results and Discussion}

\subsection{Characteristics of $\mathrm{Sn}-3.5 \mathrm{Ag}-\mathrm{Bi}$ solder alloys}

Figure 3 shows the melting point of $\mathrm{Sn}-3.5 \mathrm{Ag}-\mathrm{Bi}$ solder alloys. The melting point of $\mathrm{Sn}-3.5 \mathrm{Ag}-\mathrm{Bi}$ decreased linearly with increasing the $\mathrm{Bi}$ content, from $221^{\circ} \mathrm{C}$ of $\mathrm{Sn}-3.5 \mathrm{Ag}$ to $210^{\circ} \mathrm{C}$ of $\mathrm{Sn}-3.5 \mathrm{Ag}-9 \mathrm{Bi}$. Sn-3.5Ag-Bi alloy with Bi content more than 3 mass $\%$ exhibited a melting point lower than $217^{\circ} \mathrm{C}$ of the ternary eutectic $\mathrm{Sn}-\mathrm{Ag}-\mathrm{Cu}$ alloy. ${ }^{1)}$ Figure 4 illustrates the wetting angle of $\mathrm{Sn}-3.5 \mathrm{Ag}-\mathrm{Bi}$ solder on $\mathrm{Cu}$ and $\mathrm{Ni}$ substrates. The wetting angles on Ni substrate as well as on $\mathrm{Cu}$ substrate decreased continuously with increasing the $\mathrm{Bi}$ addition, which could be attributed to a decrease in the

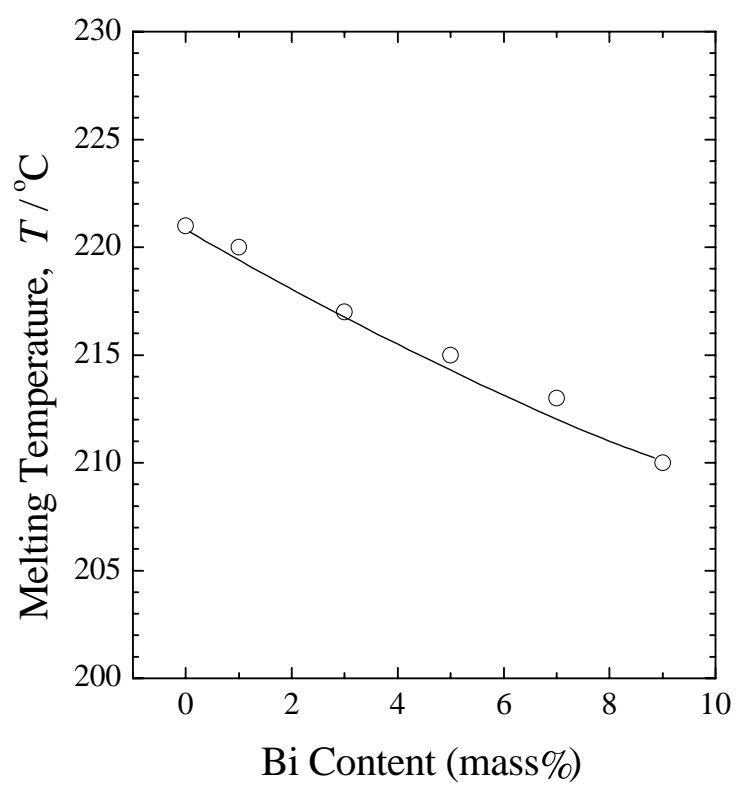

Fig. 3 Melting point of $\mathrm{Sn}-3.5 \mathrm{Ag}-\mathrm{Bi}$ alloys as a function of the Bi content.

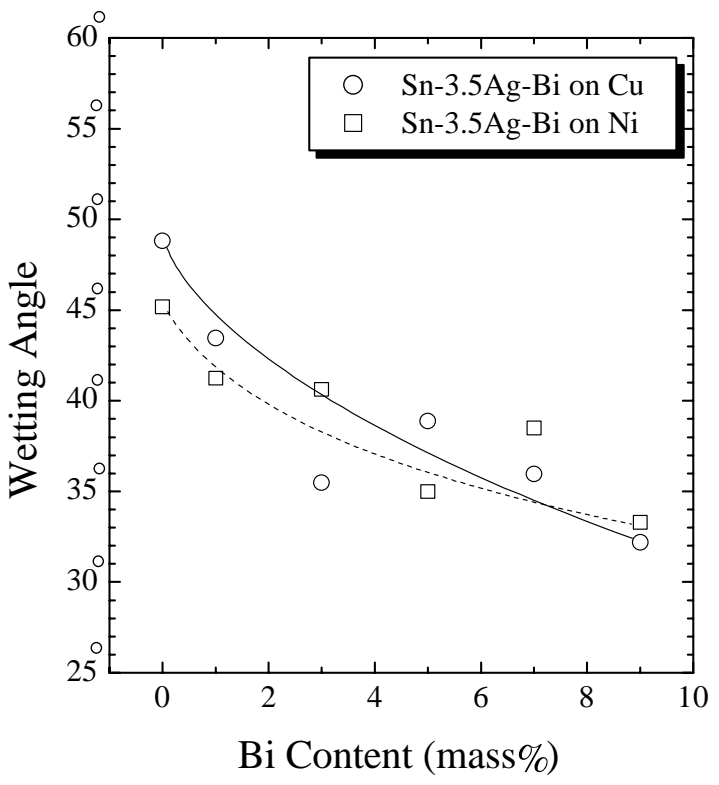

Fig. 4 Wetting angle of $\mathrm{Sn}-3.5 \mathrm{Ag}-\mathrm{Bi}$ alloys on $\mathrm{Cu}$ and Ni substrates. solder-flux interfacial tension with increasing the amount of Bi addition. ${ }^{6}$ )

Figure 5 shows the tensile strength of $\mathrm{Sn}-3.5 \mathrm{Ag}-\mathrm{Bi}$ solder alloys as a function of the $\mathrm{Bi}$ content. Tensile strength increased with increasing the $\mathrm{Bi}$ content. While the increase in the tensile strength with $\mathrm{Bi}$ addition less than 5 mass $\%$, the solubility limit of $\mathrm{Bi}$ in $\mathrm{Sn}$, could be due to solid solution hardening, further strength increment with $\mathrm{Bi}$ addition beyond its solubility limit would be attributed to Bi precipitation. ${ }^{7,8)}$ Figure 6 shows SEM micrographs of $\mathrm{Sn}-3.5 \mathrm{Ag}-\mathrm{Bi}$ solder alloys. Bi precipitates were clearly observed for $\mathrm{Sn}-3.5 \mathrm{Ag}-\mathrm{Bi}$ alloys with $\mathrm{Bi}$ content more than 3 mass $\%$. Xiao et al. ${ }^{10)}$ also observed an increase in tensile strength of $\mathrm{Sn}-\mathrm{Ag}$ alloy with $\mathrm{Bi}$ addition and reported with TEM analysis that the strength increase in $\mathrm{Sn}-3.4 \mathrm{Ag}-4.8 \mathrm{Bi}$ alloy was caused by Bi precipitation.

Figure 7 shows the fracture energy of $\mathrm{Sn}-3.5 \mathrm{Ag}-\mathrm{Bi}$ solder alloys as a function of the $\mathrm{Bi}$ content. The fracture energy was calculated from the integral of the area under the stressstrain curve. The fracture energy of $\mathrm{Sn}-3.5 \mathrm{Ag}-\mathrm{Bi}$ alloys also increased with increasing the $\mathrm{Bi}$ addition. However, the increment of the fracture energy was less than that of the tensile strength due to the decrease in ductility with increasing the $\mathrm{Bi}$ content. It has been suggested that the decrease in the ductility of $\mathrm{Sn}-3.5 \mathrm{Ag}-\mathrm{Bi}$ alloys is caused by the irregularly shaped $\mathrm{Ag}_{3} \mathrm{Sn}$ second phase particles in the $\mathrm{Sn}$-rich matrix. ${ }^{8)}$

Our results on $\mathrm{Sn}-3.5 \mathrm{Ag}-\mathrm{Bi}$ solder alloys confirmed that the solder characteristics of $\mathrm{Sn}-3.5 \mathrm{Ag}$ can be improved with $\mathrm{Bi}$ addition to decrease the melting temperature, to promote wetting to $\mathrm{Cu}$ and $\mathrm{Ni}$ substrates, and to increase the strength and fracture energy.

\subsection{Shear strength and fracture behavior of $\mathrm{Sn}-3.5 \mathrm{Ag}$ Bi solder bumps}

Figure 8 shows the shear strength of $\mathrm{Sn}-3.5 \mathrm{Ag}-\mathrm{Bi}$ solder bumps with variation of the $\mathrm{Bi}$ content. To prepare the solder bumps, $\mathrm{Sn}-3.5 \mathrm{Ag}-\mathrm{Bi}$ solder discs of $0.8 \mathrm{~mm}$ diameter were reflowed on $0.64 \mathrm{~mm} \mathrm{Au} / \mathrm{Ni} / \mathrm{Cu} \mathrm{UBM}$ for 30 and $60 \mathrm{~s}$. The

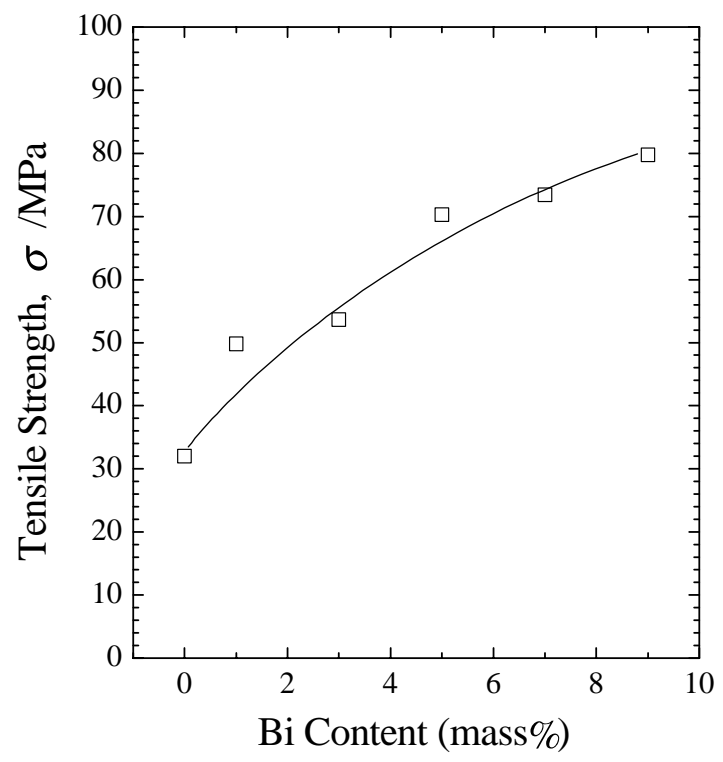

Fig. 5 Tensile strength of $\mathrm{Sn}-3.5 \mathrm{Ag}-\mathrm{Bi}$ alloys as a function of the $\mathrm{Bi}$ content. 

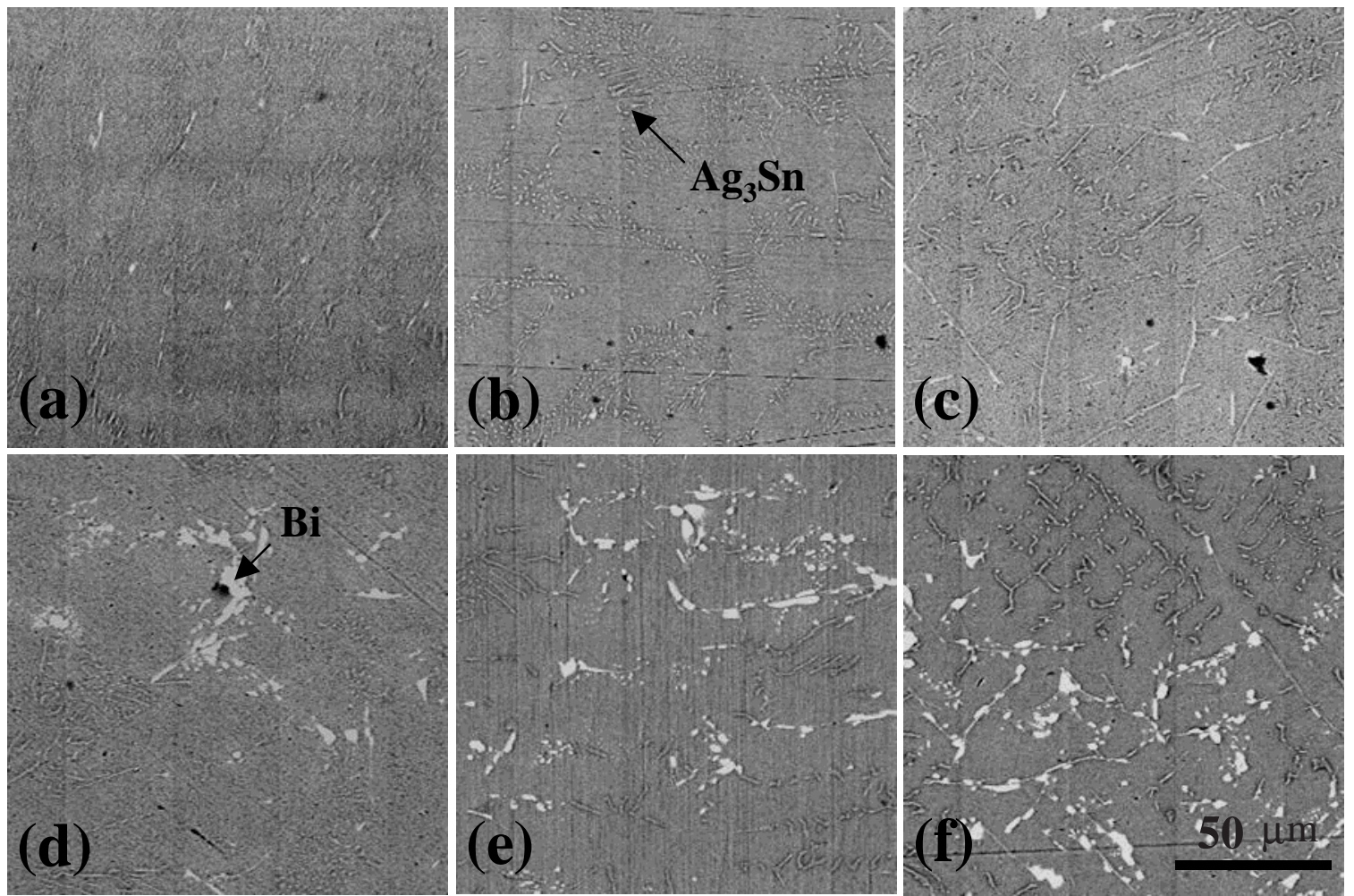

Fig. 6 SEM micrographs of Sn-3.5Ag-Bi alloys with Bi content of (a) 0 mass $\%$, (b) 1 mass $\%$, (c) 3 mass $\%$, (d) 5 mass $\%$, (e) 7 mass $\%$, and (f) 9 mass $\%$.

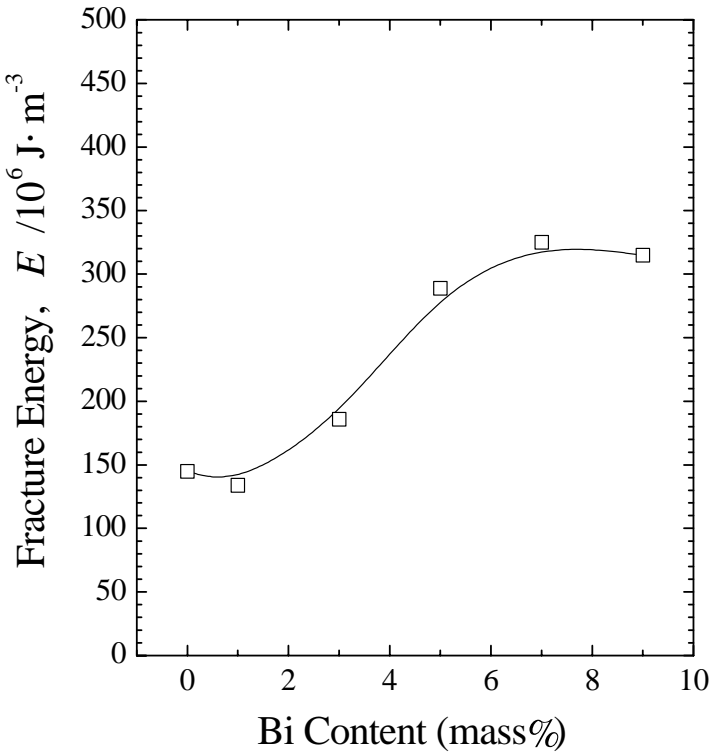

Fig. 7 Fracture energy of $\mathrm{Sn}-3.5 \mathrm{Ag}-\mathrm{Bi}$ alloys as a function of the $\mathrm{Bi}$ content.

shear strength of the solder bumps increased with Bi addition up to 5 mass \%, and was kept almost unchanged with further increase of $\mathrm{Bi}$ addition.

During ball shear test, ductile fracture occurred in the solder for all the solder bumps with 0-9 mass\% Bi addition regardless of the reflow time of 30 or $60 \mathrm{~s}$. As the shear crack propagated in the solder, the shear strength of the solder bumps should be related to the mechanical properties of the solder alloys. As shown in Fig. 5, tensile strength of Sn$3.5 \mathrm{Ag}-\mathrm{Bi}$ alloys increased by solid solution hardening with

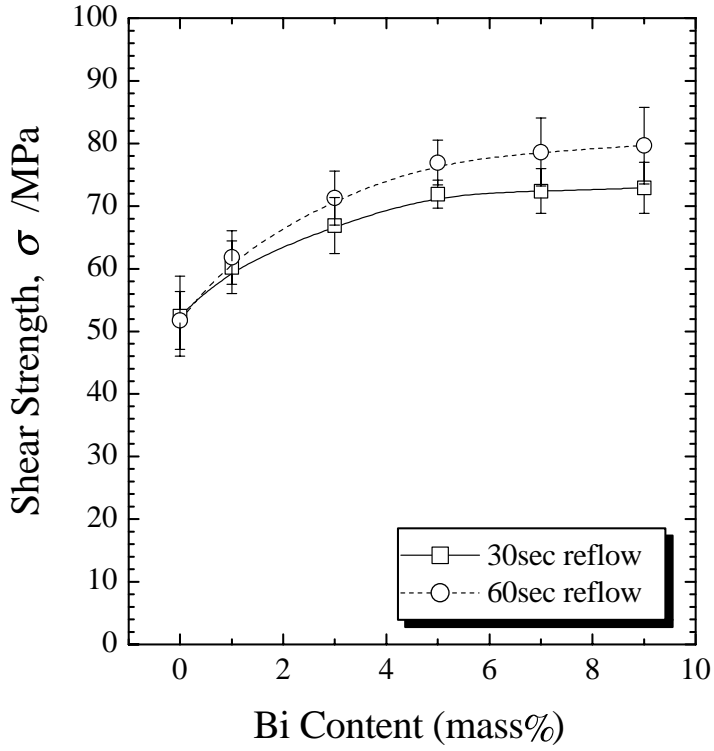

Fig. 8 Shear strength of $\mathrm{Sn}-3.5 \mathrm{Ag}-\mathrm{Bi}$ solder bumps, reflowed on $\mathrm{Au} / \mathrm{Ni} / \mathrm{Cu}$ for 30 and 60 seconds, as a function of the Bi content.

$\mathrm{Bi}$ addition less than 5 mass $\%$, and by dispersion hardening of $\mathrm{Bi}$ precipitates with $\mathrm{Bi}$ addition beyond its solubility limit. ${ }^{7,8)}$ With applying such strengthening mechanisms to the shear strength change of the solder bumps (Fig. 8), it seems that dispersion hardening with $\mathrm{Bi}$ precipitates is not as effective as solid solution hardening is to improve the shear strength of $\mathrm{Sn}-3.5 \mathrm{Ag}-\mathrm{Bi}$ solder bumps. Considering adverse effect of $\mathrm{Bi}$ addition on thermal fatigue, ${ }^{8,11)} \mathrm{Bi}$ addition in $\mathrm{Sn}-3.5 \mathrm{Ag}-$ Bi can be suggested to be less than 5 mass $\%$ for the solder bumping process. 


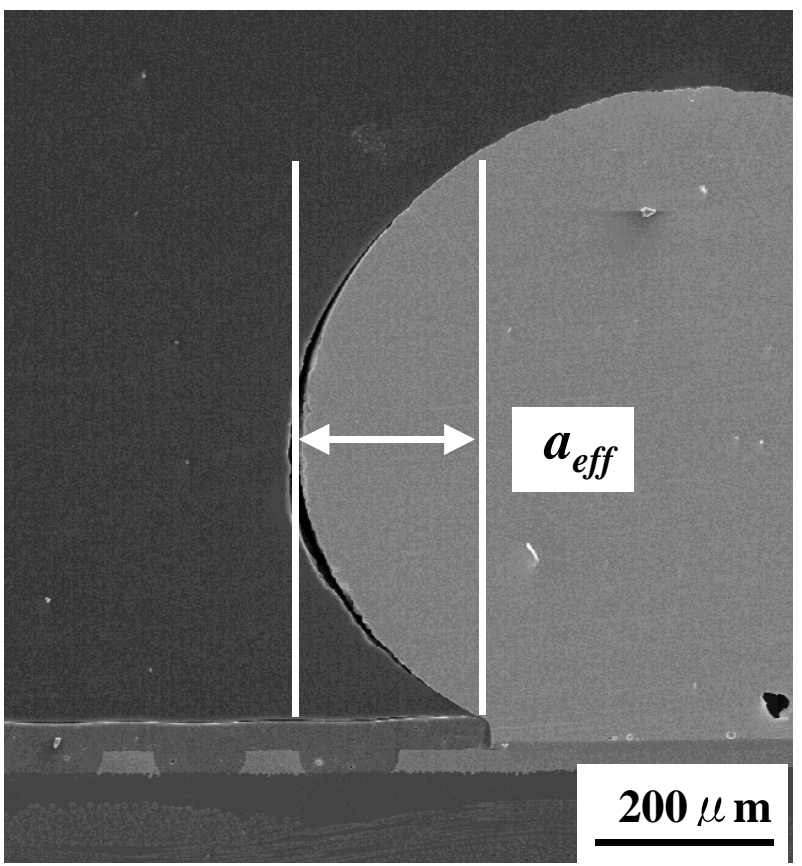

Fig. 9 Cross-sectional SEM micrograph of the Sn-3.5Ag-Bi solder bump.

During ball shear test, shear mode loading is applied to the solder bump and the neck edge corner shown in Fig. 1 acts as a notch crack tip where the solder joint failure initiates. As shown in Fig. 9, the distance from the contact point of the bump-shear tip to the neck edge corner may be defined as the effective crack size $a_{\text {eff }}$ for shear-mode fracture. As the solder is soft at room temperature, however, plastic deformation at the neck edge corner occurs freely and the plastic zone spreads through the entire area of the solder bump adjacent to the bump/UBM interface. With large scale plasticity during ball shear test, thus, linear elastic fracture mechanics with the effective crack size $a_{\text {eff }}$ are not applicable, but J integral should be used for the shear-mode fracture of the solder bump.

As shown in Fig. 8, the shear strength was improved by increasing the reflow time from 30 to $60 \mathrm{~s}$ for all compositions of the solder bumps. Such increase in the shear strength could be related to dissolution of $\mathrm{Ni}$ in $\mathrm{Au} / \mathrm{Ni} / \mathrm{Cu} \mathrm{UBM}$ to the solder during reflow. As reported for $63 \mathrm{Sn}-37 \mathrm{~Pb}$ reflow, ${ }^{12)} \mathrm{Au}$ layer in $\mathrm{Au} / \mathrm{Ni} / \mathrm{Cu} \mathrm{UBM}$ is dissolved completely into $\mathrm{Sn}-3.5 \mathrm{Ag}$ during reflow, exposing Ni layer to the molten solder. ${ }^{13,14}$ Contrary to low solubility limit of $\mathrm{Ni}, 0.052$ at $\%$, in $63 \mathrm{Sn}-$ $37 \mathrm{~Pb}$ at $220^{\circ} \mathrm{C}$, solubility limit of $\mathrm{Ni}$ in $\mathrm{Sn}-3.5 \mathrm{Ag}$ at $250^{\circ} \mathrm{C}$ is relatively high $(0.28$ at $\%) .{ }^{15)}$ However, the dissolution rate of $\mathrm{Ni}$ into Sn-rich solders is slow, ${ }^{15)}$ and the amount of Ni dissolved into $\mathrm{Sn}-3.5 \mathrm{Ag}-\mathrm{Bi}$ would increase with increasing the reflow time from 30 to $60 \mathrm{~s}$ in this study. This might cause the solid solution hardening effect of $\mathrm{Ni}$ and increase the shear strength of the Sn-3.5Ag-Bi after reflowing for $60 \mathrm{~s}$.

\section{Conclusions}

With studying on the mechanical properties of $\mathrm{Sn}-3.5 \mathrm{Ag}-$ $\mathrm{Bi}$ alloys and the shear strength of $\mathrm{Sn}-3.5 \mathrm{Ag}-\mathrm{Bi}$ solder bumps reflowed on $\mathrm{Au} / \mathrm{Ni} / \mathrm{Cu} \mathrm{UBM}$, the following conclusions could be made:

(1) Melting point of $\mathrm{Sn}-3.5 \mathrm{Ag}-\mathrm{Bi}$ decreased linearly with increasing the $\mathrm{Bi}$ content, from $221^{\circ} \mathrm{C}$ of $\mathrm{Sn}-3.5 \mathrm{Ag}$ to $210^{\circ} \mathrm{C}$ of $\mathrm{Sn}-3.5 \mathrm{Ag}-9 \mathrm{Bi}$. Wetting angle of $\mathrm{Sn}-3.5 \mathrm{Ag}-\mathrm{Bi}$ decreased continuously on $\mathrm{Cu}$ and $\mathrm{Ni}$ substrates with increasing the $\mathrm{Bi}$ addition.

(2) Tensile strength and fracture energy of $\mathrm{Sn}-3.5 \mathrm{Ag}-\mathrm{Bi}$ alloys increased with increasing the $\mathrm{Bi}$ addition. However, the increment of the fracture energy was less than that of the tensile strength due to the decrease in ductility with Bi addition.

(3) Shear strength of $\mathrm{Sn}-3.5 \mathrm{Ag}-\mathrm{Bi}$ solder bumps increased with $\mathrm{Bi}$ addition up to 5 mass\%, and was kept almost unchanged with further increase of Bi addition. Dispersion hardening with $\mathrm{Bi}$ precipitates may not be as effective as solid solution hardening to improve the shear strength of solder bumps, and $\mathrm{Bi}$ addition in $\mathrm{Sn}-3.5 \mathrm{Ag}-\mathrm{Bi}$ can be suggested to be less than 5 mass $\%$.

\section{Acknowledgements}

This work was supported by Center for Electronic Packaging Materials of Korea Science and Engineering Foundation.

\section{REFERENCES}

1) K. Suganuma: Solid State Mater. Sci. 5 (2001) 55-64.

2) M. Abtew and G. Selvaduray: Mater. Sci. Eng. 27 (2000) 95-141.

3) J. W. Jang, D. R. Frear, T. Y. Lee and K. N. Tu: J. Appl. Phys. 88 (2000) 6359-6363.

4) S. K. Kang, D. Y. Shih, K. Fogel, P. Lauro, M. J. Yim, G. Advocate, M. Griffin, C. Goldsmith, D. W. Henderson, T. Gosselin, D. King, J. Konrad, A. Sarkhel and K. J. Putlitz: Proc. 51 st Electronic Components and Technol. Conf., (IEEE, 2001) pp. 448-454.

5) E. Bradley III and J. Hranisavljevic: Proc. 50th Electronic Components and Technol. Conf., (IEEE, 2000) pp. 1443-1448.

6) P. T. Vianco and J. A. Rejent: J. Electron. Mater. 28 (1999) 1127-1132.

7) P. T. Vianco and J. A. Rejent: J. Electron. Mater. 28 (1999) 1138-1143.

8) Y. Kariya and M. Otsuka: J. Electron. Mater. 27 (1997) 866-870.

9) JESD22-B117 “BGA Ball Shear," July 2000, JEDEC Solid State Technology Association.

10) L. Xiao, J. Liu, Z. Lai, L. Ye and A. Tholen: Proc. Int. Symp. Adv. Packaging Mater, (International Microelectronics \& Packaging Society, 2000) pp. 145-151.

11) J. R. Oliver, J. Liu and Z. Lai: Proc. Int. Symp. Adv. Packaging Mater, (International Microelectronics \& Packaging Society, 2000) pp. 152156.

12) A. Zribi, R. R. Chromik, R. Presthus, J. Clum, K. Teed, L. Zavalij, J. De Vita, J. Tova and E. J. Cotts: Proc. IEEE/CPMT Int. Electronics Manufacturing Technol. Symp., (IEEE, 1999) pp. 451-457.

13) K. Y. Lee and M. Li: Metall. Mater. Trans. 32A (2001) 2666-2668.

14) K. Y. Lee, M. Li, D. R. Olsen, W. T. Chen, B. T. C. Tan and S. Mhaisalkar: Proc. 51st Electronic Components Technol. Conf., (IEEE, 2001) pp. 478-485.

15) K. Zeng and K. N. Tu: "Reliability Issues of Pb-free Solder Joints in Electronic Packaging Technology," submitted to Mater. Sci. Eng. (2001). 